\title{
Casca de arroz carbonizada como substrato para produção de mudas de tamboril-da-mata e garapeira
}

\section{Carbonized rice hull as substratum to produce tamboril-da-mata and garapeira seedlings}

\author{
Fabio Luiz Fleig Saidelles ${ }^{1}$; Marcos Vinicius Winckler Caldeira ${ }^{2 *}$; \\ Waldir Nagel Schirmer ${ }^{3}$; Huezer Viganô Sperandio ${ }^{4}$
}

\begin{abstract}
Resumo
A produção de mudas florestais, em quantidade e qualidade, é uma das fases mais importantes para o estabelecimento de bons povoamentos com espécies nativas. Nesse sentido, o substrato é o fator que exerce influência significativa no desenvolvimento das mudas, e vários são os materiais que podem ser utilizados na sua composição original ou combinados. O objetivo do trabalho foi avaliar a influência da casca de arroz carbonizada como substrato na produção de mudas de Tamboril-da-mata (Enterolobium contortisiliquum (Vell.) Morong) e Garapeira (Apuleia leiocarpa (Vogel) J.F. Macbr.). O experimento foi realizado em Santa Maria - RS. O delineamento experimental utilizado foi o inteiramente casualizado, sendo constituído por 5 tratamentos (T1: 0\% de Cascca de Arroz Carbonizada (CAC) + 100\% de Solo; T2: $25 \%$ de CAC $+75 \%$ de Solo; $73: 50 \%$ de CAC $+50 \%$ de Solo; T4: $75 \%$ de CAC $+25 \%$ de Solo; T5: $100 \%$ de CAC $+0 \%$ de Solo), com 5 repetições. Em cada repetição foram avaliadas as médias de 10 plantas. De modo geral, houve efeito da adição da casca de arroz carbonizada ao solo no desenvolvimento de ambas as espécies. Mudas de Apuleia leiocarpa produzidas com altas proporções de casca de arroz carbonizada ao solo tiveram um efeito negativo no seu desenvolvimento. No entanto, para produzir mudas de Enterolobium contortisiliquum com um adequado padrão de qualidade recomenda-se utilizar $50 \%$ de casca de arroz carbonizada $+50 \%$ de solo.
\end{abstract}

Palavras-chave: Enterolobium contortisiliquum (Vell.) Morong, Apuleia leiocarpa (Vogel) J.F. Macbr, sementes florestais, qualidade de mudas

\begin{abstract}
The production of forest seedlings, in quantity and quality, is one of the most important steps for the establishment of good stands with native species. Therefore, the substrate is the factor that makes a significant influence in the development of seedlings and many materials can be used in its original composition or combined. This work focus on evaluating the influence of carbonized rice hull as substrate for the production of seedlings of Enterolobium contortisiliquum (Vell.) Morong) and Apuleia leiocarpa (Vogel) JF Macbr.). The experiment was accomplished in Santa Maria-RS. The experiment had a completely randomized design, with 5 treatments (T1: $0 \%$ carbonized rice hull $+100 \%$ soil; T2:
\end{abstract}

1 D.Sc. Pesquisador da FEPAGRO.E-mail: fabio-saidelles@fepagro.rs.gov.br

2 Prof. D.Sc. Departamento de Engenharia Florestal. Centro de Ciências Agrárias. Universidade Federal do Espírito Santo. Alto Universitário, s/n. Caixa Postal: 16, CEP: 29500-000. Alegre/ES, Brasil. E-mail: caldeiramv@yahoo.com.br.

3 Prof. D.Sc. Departamento de Engenharia Ambiental, Setor de Ciências Agrárias e Ambientais. Universidade Estadual do CentroOeste (Unicentro), Campus Universitário de Irati. Rodovia PR 153 - km 07, Bairro: Riozinho - Caixa Postal: 21, CEP: 84500000, Irati/PR, Brasil. E-mail: wanasch@yahoo.com.br

4 Graduando em Engenharia Florestal. Departamento de Engenharia Florestal. Centro de Ciências Agrárias. Universidade Federal do Espírito Santo. E-mail: huezer@gmail.com

* Autor para correspondência 
$25 \%$ carbonized rice hull $+75 \%$ soil; T3: $50 \%$ carbonized rice hull $+50 \%$ soil; T4: $75 \%$ carbonized rice hull $+25 \%$ soil; T5: $100 \%$ carbonized rice hull $+0 \%$ de soil), and 5 replications and 10 plants per plot. Carbonized rice hull influenced the development of both species. High proportions of carbonized rice hull produced Apuleia leiocarpa seedlings with had bad development. However, to produce seedlings of Enterolobium contortisiliquum to an adequate standard of quality it is recommended to use $50 \%$ of carbonized rice hull $+50 \%$ of soil.

Key words: Enterolobium contortisiliquum (Vell.) Morong, Apuleia leiocarpa (Vogel) JF Macbr, forest seeds, quality of seedlings

\section{Introdução}

A grande exploração de florestas nativas quer seja para uso com a finalidade de ocupação agrícola e/ou pecuário faz com que diminua as reservas de madeira e provoque um desequilíbrio ambiental. Atualmente, observa-se o uma preocupação em relação a estas perdas, assim como, maior fiscalização com exigências de ações compensatórias. Neste contexto, a demanda de mudas de espécies florestais nativas para recuperação de áreas alteradas tem aumentado.

Apesar disto, os viveiros que focam seus esforços para a produção de espécies nativas são aqueles vinculados às instituições públicas de pesquisa, ensino e viveiros comerciais de pequena escala. Este fato, provavelmente ocorre devido à grande complexidade na produção de espécies nativas, considerando: forma de manejo, exigência nutricional e hídrica, manejo, substrato, tipo e tamanho de recipiente.

Assim, visando à produção de espécies nativas que apresentem potencial para recuperação de áreas alteradas devem-se buscar primeiramente, muda de qualidade a partir da análise de desenvolvimento sob diferentes condições.

Conforme Gomes et al. (2002), os parâmetros morfológicos são os mais utilizados na determinação do padrão de qualidade das mudas, tendo uma compreensão mais intuitiva por parte dos viveiristas, no entanto, ainda são necessárias definições mais concretas para responder às exigências, quanto à sobrevivência e ao crescimento, diante das adversidades encontradas no campo após o plantio.
De forma semelhante, Carneiro (1995) descreveu que as mudas com padrão de qualidade são fundamentais para o desempenho do povoamento após o plantio, mencionando parâmetros como altura, diâmetro do colo, peso seco da parte aérea e radicular, peso seco total, Índice de Qualidade de Dickson, entre outros.

Autilizaçãode novos tipos de recipientes segundo, Fernandes, Ferreira e Stape (1986) exige estudos visando à adequação do substrato, de acordo com suas particularidades. Assim, é possível propiciar boas condições para o desenvolvimento das mudas e adequada interação entre o sistema radicular e o substrato. A produção de mudas em um recipiente onde as raízes ficam confinadas a pequenos volumes, deve possibilitar a muda condições de permanecer no viveiro, durante o período de formação e propiciar seu desenvolvimento no campo.

Enquanto as mudas permanecem no viveiro o fator que deverá obrigatoriamente ser levado em consideração é o substrato que será utilizado na produção de mudas, devendo possuir características como consistência, boa estrutura, alta capacidade de retenção de água e alta porosidade. O substrato não deve se expandir, contrair ou apresentar substâncias tóxicas, devendo ser disponível e padronizado (GONÇALVES; POGGIANI, 1996).

Klein et al. (2002), ao avaliar as alterações das propriedadesfísico-hídricas desubstratoscomerciais, misturados com a casca de arroz carbonizada em diferentes proporções, observaram que esta pode ser utilizada para melhorar as propriedades físico-hídricas de substratos, propiciando melhor porosidade. 
Conforme Tabajara e Colônia (1986) as cascas de arroz carbonizada correspondem a aproximadamente $20 \%$ do peso dos substratos. Segundo os autores acima, uma vez lançadas no meio ambiente, as cascas de arroz carbonizada, devido à sua lenta biodegradação, permanecem inalteradas por longos períodos de tempo. A casca de arroz, quando carbonizada, apresenta alta capacidade de drenagem, fácil manuseio, peso reduzido, $\mathrm{pH}$ levemente alcalino, forma floculada, livre de patógenos e nematóides, teor adequado de $\mathrm{K}$ e Ca que são dois macronutrientes essenciais para o desenvolvimento vegetal.

As características da casca de arroz carbonizada, associadas ao baixo custo de transporte, dada a sua leveza, aproveitamento de material, a princípio, visto como negativo ao meio ambiental (MINAMI, 1995) e possibilidade de ser utilizado por produtores com baixo poder de investimento para aquisição de substratos comerciais, sugere a necessidade de avaliar este material como componente de substrato alternativo.

As espécies selecionadas para a realização deste trabalho foram Enterolobium contortisiliquum (Vell.) Morong (Tamboril-da-mata) e Apuleia leiocarpa (Vogel) J.F. Macbr. (Garapeira) ambas da família Fabaceae (Leguminosae), que ocorrem naturalmente, em quase todos os estados brasileiros. Consideradas pioneiras em formações secundárias. O grande potencial destas espécies para recuperação de áreas alteradas tem estimulado a realização de pesquisas. A madeira de ambas as espécies tem utilidade ampla.

O objetivo deste trabalho foi avaliar a utilização da casca de arroz carbonizada misturada ao solo em diferentes proporções, como forma de constituir substrato alternativo para produção de mudas de Tamboril-da-mata e Garapeira.

\section{Material e métodos}

O experimento foi realizado no viveiro florestal do Centro de Pesquisas de Recursos Florestais (CPRF), pertencente à Fundação Estadual de Pesquisa Agropecuária - FEPAGRO, localizado em Santa Maria-RS.

O clima da região, segundo a classificação de Köppen, é subtropical do tipo Cfa, que se caracteriza por apresentar chuvas todos os meses do ano, podendo haver déficit hídrico nos meses de verão e precipitação média anual entre 1500 e $1700 \mathrm{~mm}$. A média térmica do verão é de $24^{\circ} \mathrm{C}$ nas áreas mais elevadas, e $32^{\circ} \mathrm{C}$, onde as altitudes são menores, e máximas absolutas em torno de $40^{\circ} \mathrm{C}$. No inverno a temperatura média do mês mais frio fica em torno $\operatorname{dos} 13^{\circ} \mathrm{C}$ (SARTORI, 1979).

As sementes de Garapeira foram coletadas no município de Restinga Seca-RS, no dia 15/01/2004. Após a coleta, as sementes foram armazenadas em câmara fria e seca, recebendo como método de superação de dormência, a imersão em água em ebulição $\left(90^{\circ} \mathrm{C}\right)$ onde permaneceram até a água atingir temperatura ambiente. A semeadura da Garapeira ocorreuno dia 10/10/2005 comemergência em 16/10/2005. As sementes de Tamboril-da-mata foram coletadas no município de Santa Maria no dia 29/05/2003 e armazenadas também em câmara fria e seca, como método para superar a dormência, as sementes foram imersas em água temperatura ambiente por 24 horas. As sementes de Tamborilda-mata foram semeadas no dia 13/09/2005 com emergência dia 18/10/2005.

$\mathrm{Na}$ semeadura, de ambas as espécies, foram distribuídas duas sementes por tubete $\left(90 \mathrm{~cm}^{3}\right.$ de substrato), manualmente, cobrindo-se as sementes com, aproximadamente, $1 \mathrm{~cm}$ de casca de arroz carbonizada. Posteriormente, foi realizado o raleio, 35 dias após a emergência, mantendo a muda mais central e desenvolvida. 
As mudas foram produzidas em tubetes cônicos de polipropileno, com volume de $90 \mathrm{~cm}^{3}$, medindo $13 \mathrm{~cm}$ de altura, $3,5 \mathrm{~cm}$ de diâmetro superior e $1 \mathrm{~cm}$ na parte inferior.

Os tratamentos foram determinados a partir da combinação de solo e casca de arroz carbonizada (CAC). Foram utilizados cinco tratamentos (T1: 0\% de Cascca de Arroz Carbonizada (CAC) $+100 \%$ de Solo; T2: $25 \%$ de CAC $+75 \%$ de Solo; T3: $50 \%$ de CAC $+50 \%$ de Solo; T4: $75 \%$ de CAC $+25 \%$ de Solo; T5: $100 \%$ de CAC $+0 \%$ de Solo). O solo foi identificado (EMBRAPA, 2006) como sendo um ARGISSOLO VERMELHO Distrófico, arênico utilizado atualmente como principal constituinte do substrato na produção das mudas dessas duas espécies, proveniente do próprio Centro de Pesquisas de Recursos Florestais. Na coleta de solo foram descartados os primeiros $15 \mathrm{~cm}$, a partir da superfície retirando-se o solo até atingir o horizonte B. A casca de arroz carbonizada (CAC) utilizada foi o resíduo do beneficiamento do arroz, proveniente da região de Santa Maria-RS.

O delineamento experimental utilizado foi inteiramente casualizado, sendo constituído por 5 tratamentos com 5 repetições. Em cada repetição foram avaliadas as médias de 10 plântulas.

Antes dainstalação do experimento os tratamentos foram analisados química e fisicamente, segundo a metodologia de Tedesco et al. (1995), apresentadas na (Tabela 1). As análises foram realizadas no Laboratório de Análises de Solo do Departamento de Solos/CCR/UFSM. Porém, as análises do substrato contendo $100 \%$ CAC foram determinados junto ao Laboratório de Química Agrícola da FEPAGRO.

Tabela 1. Análises químicas e físicas dos tratamentos utilizados na produção de mudas de Enterolobium contortisiliquum e Apuleia leiocarpa.

\begin{tabular}{|c|c|c|c|c|c|}
\hline Análise & $\begin{array}{c}0 \% \text { CAC } \\
+ \\
100 \% \text { Solo }\end{array}$ & $\begin{array}{c}25 \% \text { CAC } \\
+ \\
75 \% \text { Solo }\end{array}$ & $\begin{array}{c}50 \% \text { CAC } \\
+ \\
50 \% \text { Solo }\end{array}$ & $\begin{array}{c}75 \% \text { CAC } \\
+ \\
25 \% \text { Solo }\end{array}$ & $\begin{array}{c}100 \% \text { CAC } \\
+ \\
0 \% \text { Solo }\end{array}$ \\
\hline pH-água $1: 1$ & 4,4 & 4,3 & 4,8 & 5,2 & 7,3 \\
\hline$\% \mathrm{MO}(\mathrm{m} / \mathrm{v})$ & 2,1 & 2,3 & 2,6 & 3,0 & - \\
\hline $\mathrm{P}\left(\mathrm{mg} \mathrm{dm} \mathrm{m}^{-3}\right)$ & 76 & 54,7 & 76 & 76 & 60 \\
\hline $\mathrm{K}\left(\mathrm{mg} \mathrm{dm} \mathrm{m}^{-3}\right)$ & 240 & 308 & 528 & 744 & 470 \\
\hline $\mathrm{Ca}\left(\mathrm{cmol}_{\mathrm{c}} \mathrm{dm}^{3}\right)$ & 2,7 & 3,1 & 3,1 & 3,0 & 1,8 \\
\hline $\operatorname{Mg}\left(\mathrm{cmol}_{\mathrm{c}} \mathrm{dm}^{3}\right)$ & 1,3 & 1,2 & 1,5 & 1,3 & 0,9 \\
\hline $\mathrm{Al}\left(\mathrm{cmol}_{\mathrm{c}}^{\mathrm{c}} \mathrm{dm}^{-3}\right)$ & 1,9 & 1,6 & 1,0 & 0,3 & - \\
\hline $\mathrm{H}+\mathrm{Al}\left(\mathrm{cmol}_{\mathrm{c}} \mathrm{dm}^{-3}\right)$ & 8,7 & 7,7 & 4,9 & 2,8 & - \\
\hline $\mathrm{CTC}_{\mathrm{ef}}\left(\mathrm{cmol}_{\mathrm{c}} \mathrm{dm}^{-3}\right)$ & 6,5 & 6,7 & 7,0 & 6,5 & - \\
\hline $\mathrm{CTC}_{\mathrm{pH} 7}\left(\mathrm{cmol}_{\mathrm{c}}^{\mathrm{c}} \mathrm{dm}^{-3}\right)$ & 13,3 & 12,8 & 10,9 & 9 & - \\
\hline Sat. Al (\%) & 29 & 24 & 14 & 5 & - \\
\hline Sat. Bases (\%) & 35 & 40 & 55 & 69 & - \\
\hline Densidade $\left(\mathrm{g} \mathrm{cm}^{-3}\right)$ & 1,34 & 1,18 & 1,04 & 0,63 & 2,25 \\
\hline
\end{tabular}

Os tratamentos não receberam adubação de base e nem correção do $\mathrm{pH}$. As adubações de cobertura foram iniciadas 30 dias após a germinação, com freqüência a cada 15 dias, finalizando 30 dias antes da avaliação do experimento. A solução utilizada constituiu da diluição de $50 \mathrm{~g}$ de NPK (5-20-20) em 15 litros de água, irrigando-se $10 \mathrm{~m}^{2}$ de canteiros, conforme o padrão desenvolvido para a produção das mudas de Enterolobium contortisiliquum e Apuleia leiocarpa, no viveiro florestal do CPRF. 
As variáveis foram analisadas 180 dias após a semeadura: a) diâmetro do coleto (DC) medido na planta, a nível do substrato, com uso de um paquímetro, b) altura da parte aérea $(\mathrm{H})$ determinada a partir do nível do substrato até a inserção da última folha, com auxílio de uma régua, c) cálculo da relação entre a altura da parte aérea e o diâmetro do coleto (RHD). O peso da massa seca da parte aérea (PMSPA) e peso da massa seca do sistema radicular (PMSR) foram obtidos a partir do material seco em estufa, onde permaneceram a $70^{\circ} \mathrm{C}$ até atingir peso constante. O peso da massa seca total (PMST) foi calculado com base na soma do PMSPA e PMSR. Foi analisada a relação entre o peso de matéria seca da parte aérea e o peso de matéria seca do sistema radicular (RPPAR), a relação entre a altura e o peso da massa seca da parte aérea (RHPPA), bem como a relação entre peso de matéria seca do sistema radicular e o peso de matéria seca da parte aérea (RPMSRPA). O Índice de Qualidade de Dickson (IQD) foi obtido pela fórmula (DICKSON; LEAF; HOSNER, 1960).

$$
\mathrm{IQD}=\frac{\operatorname{PMST}_{(\mathrm{g})}}{\mathrm{H}_{(\mathrm{cm})} / \mathrm{DC}_{(\mathrm{mm})}+\operatorname{PMSPA}_{(\mathrm{g})} / \mathrm{PMSR}_{(\mathrm{g})}}
$$

Como os tratamentos utilizados foram considerados quantitativos, usou-se regressão, procurando-se a equação, dentre os modelos linear, quadrático e cúbico que apresentou o grau significativo a $0,05 \%$.

\section{Resultados e discussão}

De modo geral, houve efeito dos tratamentos sobre o desenvolvimento das mudas de Enterolobium contortisiliquum e Apuleia leiocarpa. Para as variáveis analisadas $(\mathrm{H}, \mathrm{DC}, \mathrm{PMSPA}, \mathrm{PMSR}$, PMST) a (Figura 1) mostra que há aumento no crescimento à medida que aumenta a adição de CAC no solo, com ponto de máximo atingindo a mistura é de $50 \%$ de CAC.

No que se refere à produção de mudas de Apuleia leiocarpa, não há necessidade da adição de CAC ao solo (Figura 2).

Segundo Mexal e Lands (1990), altura da parte aérea das mudas fornece uma excelente estimativa da predição do crescimento inicial da mudas no campo, sendo tecnicamente aceita como uma boa medida do potencial de desempenho das mudas. Também Gomes et al. (2002) citam que a altura da parte aérea, quando avaliada isoladamente, é um parâmetro para expressar a qualidade das mudas, contudo, recomendam que os valores devem ser analisados combinados com outros parâmetros tais como: diâmetro do coleto, relação peso das raízes/ peso da parte aérea. Nesse sentido, a altura da parte aérea combinada com o diâmetro do coleto constitui um dos mais importantes parâmetros morfológicos para estimar o crescimento das mudas após o plantio definitivo no campo (CARNEIRO, 1995).

O diâmetro do coleto é facilmente mensurável, não sendo um método destrutivo, considerado por muitos pesquisadores um dos mais importantes parâmetros para estimar a sobrevivência logo após o plantio de mudas de diferentes espécies florestais (GOMES et al., 2002). Daniel et al. (1997) comentam também que o diâmetro do coleto, em geral, é o mais observado para indicar a capacidade de sobrevivência das mudas no campo, e pode auxiliar na definição das doses de fertilizantes a serem aplicadas na produção de mudas. Nesse sentido, o trabalho sugere que se a intenção for produzir mudas de Enterolobium contortisiliquum com boa altura da parte aérea e/ou diâmetro do coleto, por exemplo, deve-se usar 25 a $50 \%$ de CAC na formulação do substrato. Cabe ressaltar que altura da parte aérea e o diâmetro do coleto das mudas quando plantadas no campo devem ter 30 a $35 \mathrm{~cm}$ e 2,2 a $2,5 \mathrm{~cm}$, respectivamente. 

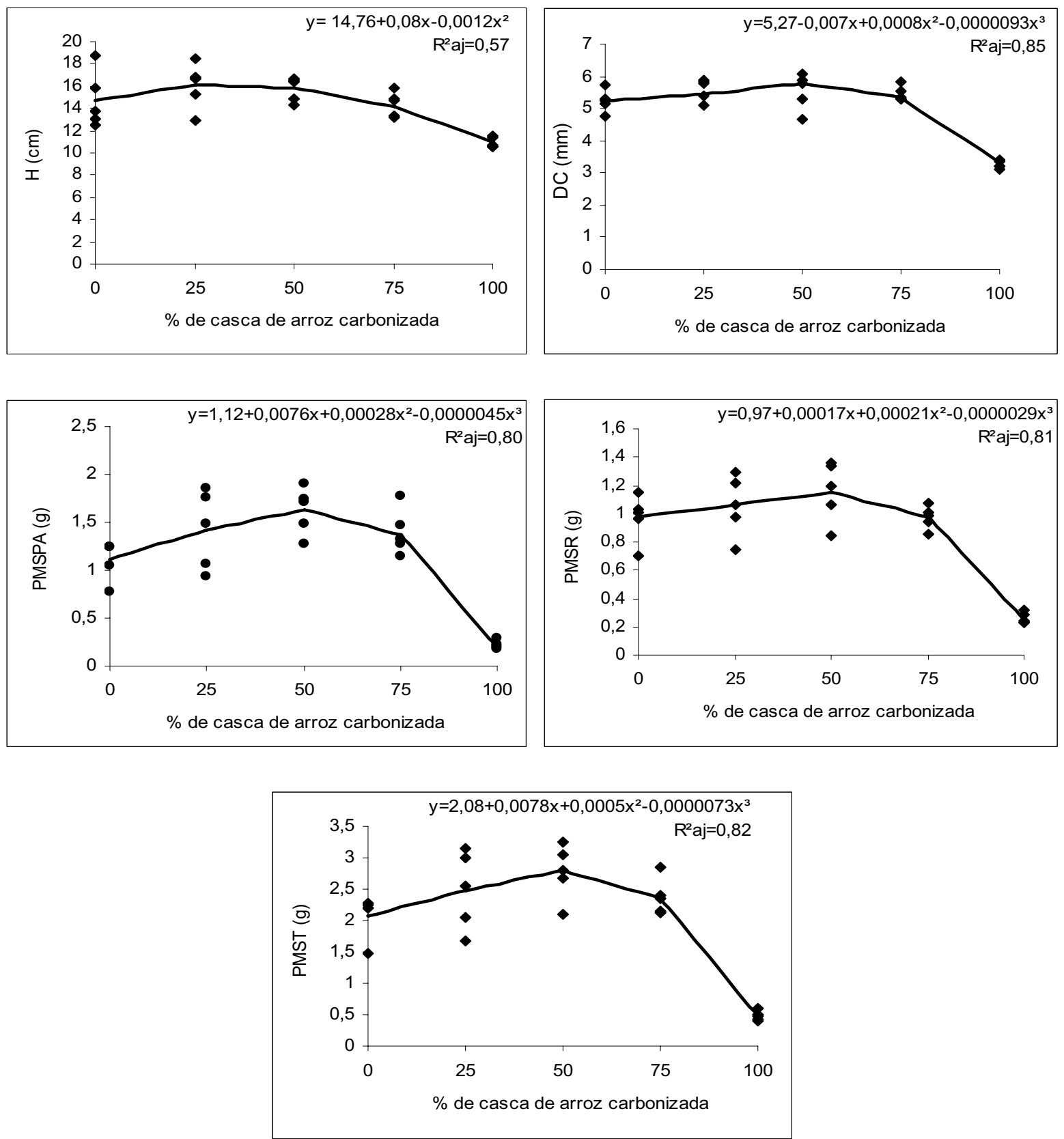

Figura 1. Regressões das variáveis biométricas para produção de mudas de Enterolobium contortisiliquum, em função da percentagem de casca de arroz carbonizada adicionada ao solo (H: altura da parte aérea; DC: diâmetro do coleto; PMSPA: peso da massa seca da parte aérea; PMSR: peso da massa seca do sistema radicular, PMST peso da massa seca total). 

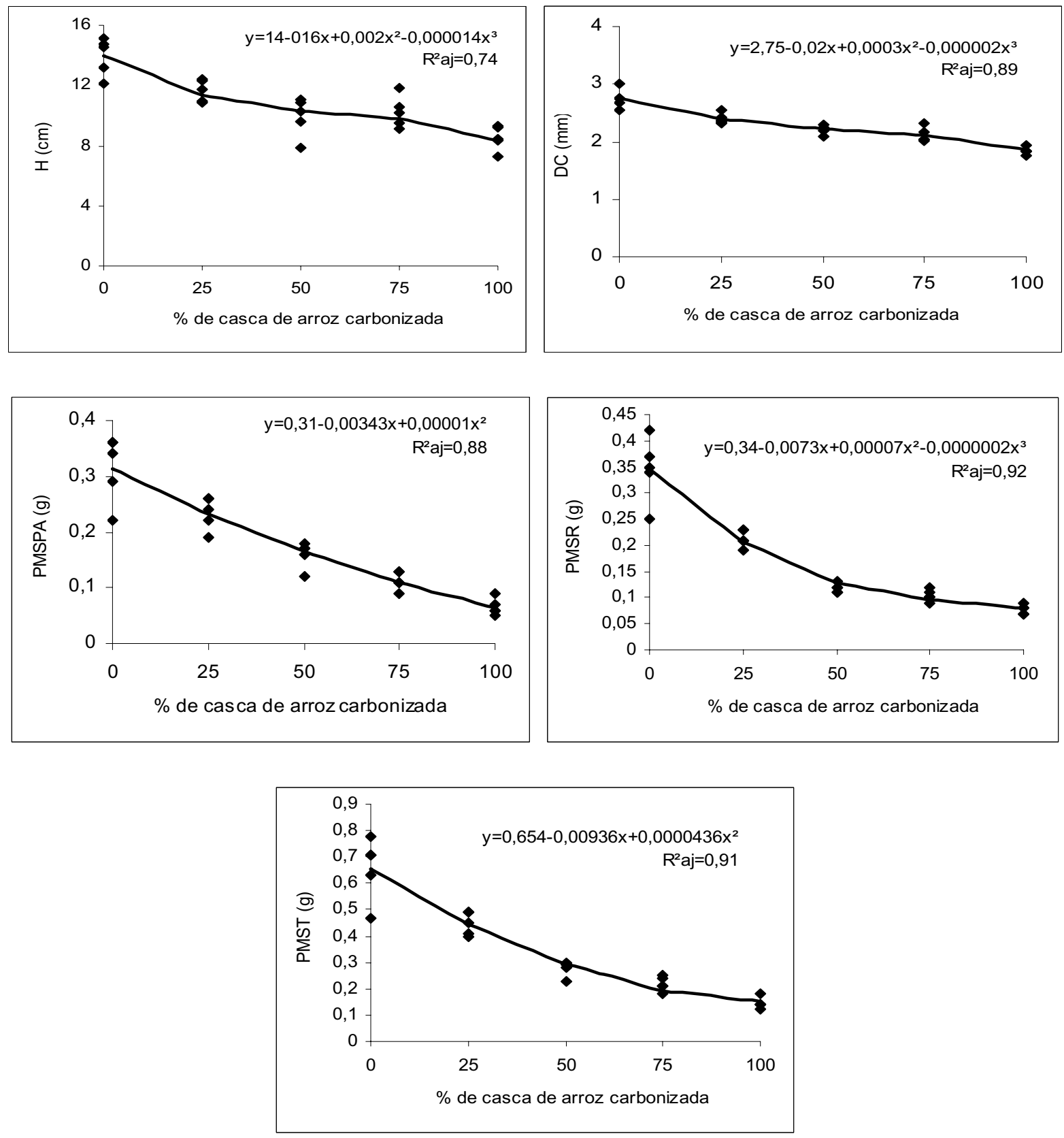

Figura 2. Regressões das variáveis biométricas para produção de mudas de Apuleia leiocarpa, em função da percentagem de casca de arroz carbonizada adicionada ao solo (H: altura da parte aérea; DC: diâmetro do coleto; PMSPA: peso da massa seca da parte aérea; PMSR: peso da massa seca do sistema radicular, PMST peso da massa seca total). 
Saidelles et al. (2006a) e Saidelles et al. (2006b) para Pinus elliotti e Cupressus lusitanico, respectivamente utilizando os mesmos tratamentos do presente estudo, bem como, mesmo tipo de solo, constataram que, o uso de $75 \%$ de CAC misturada ao solo proporcionou, para ambas as espécies as obtenções de mudas onde às médias dos parâmetros biométricos avaliados não diferiram entre si.

Trabalhando com mudas de Eucalyptus saligna, durante a fase de viveiro, Saidelles et al. (2006c), observaram que a espécie apresentou comportamento semelhante ao da Apuleia leiocarpa, onde os melhores tratamentos foram aqueles que utilizaram as menores proporções de CAC misturada ao solo na constituição do substrato.

Tanto Vallone et al. (2004) para mudas de cafeeiro como Aguiar et al. (1992) para mudas de Eucalyptus grandis observaram que o uso de 60 a $70 \%$ de CAC em substituição ao substrato comercial utilizado, propiciou melhor desenvolvimento das mudas na fase de viveiro. Porém, Salles et al. (2006) observaram que para mudas de Acacia mearnsii, a utilização de mais de $50 \%$ de CAC, juntamente com solo (ARGISSOLO VERMELHO Distrófico, arênico), na constituição do substrato, influenciou negativamente a qualidade das mudas produzidas, comportamento este semelhante ao da espécie Enterolobium contortisiliquum.

Em geral, mudas de Enterolobium contortisiliquum produzidas com mais de $50 \%$ de CAC ao solo não responderam de forma positiva aos parâmetros avaliados. A casca de arroz carbonizada, segundo Gonçalves e Poggiani (1996), reduz a capacidade de retenção de água do substrato, possui índices de $\mathrm{pH}$ muito elevados $(>6,5)$, podendo provocar deficiências de micronutrientes, baixas concentrações de $\mathrm{NeS}$, relativamente aos compostos orgânicos, apresentam baixa CTC efetiva $(<100$ $\mathrm{mmol}_{\mathrm{c}} \mathrm{dm}^{-3}$ ) e relação $\mathrm{C}: \mathrm{N}$ muito alta.

Estudo realizado por Oliveira et al. (2008), em geral, observaram que o substrato composto por
$50 \%$ casca de arroz carbonizada $+40 \%$ de esterco de galinha $+3 \%$ de terra de barranco $+7 \%$ de areia + fertilizante + calcário não apresentou condições favoráveis para as espécies (Schinus terebinthifolius Raddi ; Cedrela fissilis Vell.; Eucalyptus grandis W. Hill ex Maiden e Acacia holocericea) na característica diâmetro do colo. Esse fato é devido aos menores valores de retenção de água e sua composição com casca de arroz carbonizada, que segundo Guerrini e Trigueiro (2004) é um material pobre em nutrientes, apresentando apenas o teor de $\mathrm{K}\left(\mathrm{K}_{2} \mathrm{O}\right)$ e $\mathrm{Mg}(\mathrm{MgO})$ mais elevado (DELLA; HÜHN; HOTZA, 2001).

Cabe ressaltar que como regra geral, na formulação de substratos para a produção de mudas por sementes, recomenda-se a utilização de mais ou menos $20-40 \%$ de um material mais poroso (vermiculita, casca de arroz carbonizada, moinha de carvão) em mistura a $60-80 \%$ de um material menos poroso (terra de subsolo, composto orgânico, húmus) (GONÇALVES; POGGIANI 1996). Porém, dependendo da espécie e do manejo empregado na produção das mudas (substrato, irrigação, recipientes, etc.), esta proporção poderá ser diferente, sendo recomendada a realização de testes no local antes da utilização de qualquer composição (WENDLING; GATTO, 2002).

Os atributos das mudas, necessários para obtenção do sucesso do plantio no campo, têm sido denominados de "qualidade de muda". Segundo Duryea (1985), a qualidade pode ser definida como aqueles atributos necessários para que uma muda sobreviva e se desenvolva após o plantio no campo. HUNT (1990), recomendou o Índice de Qualidade de Dickson (IQD) como sendo bom indicador da qualidade de muda de Pseudotsuga menziesii (Mirb.) Franco e Picea abies L.

À medida que aumenta a percentagem de CAC diminui os índices IQD e RPPAR das mudas de Enterolobium contortisiliquum. Porém, com a utilização de $75 \%$ de CAC ocorre aumento nas relações RHD e RHPPA (Figura 3). 

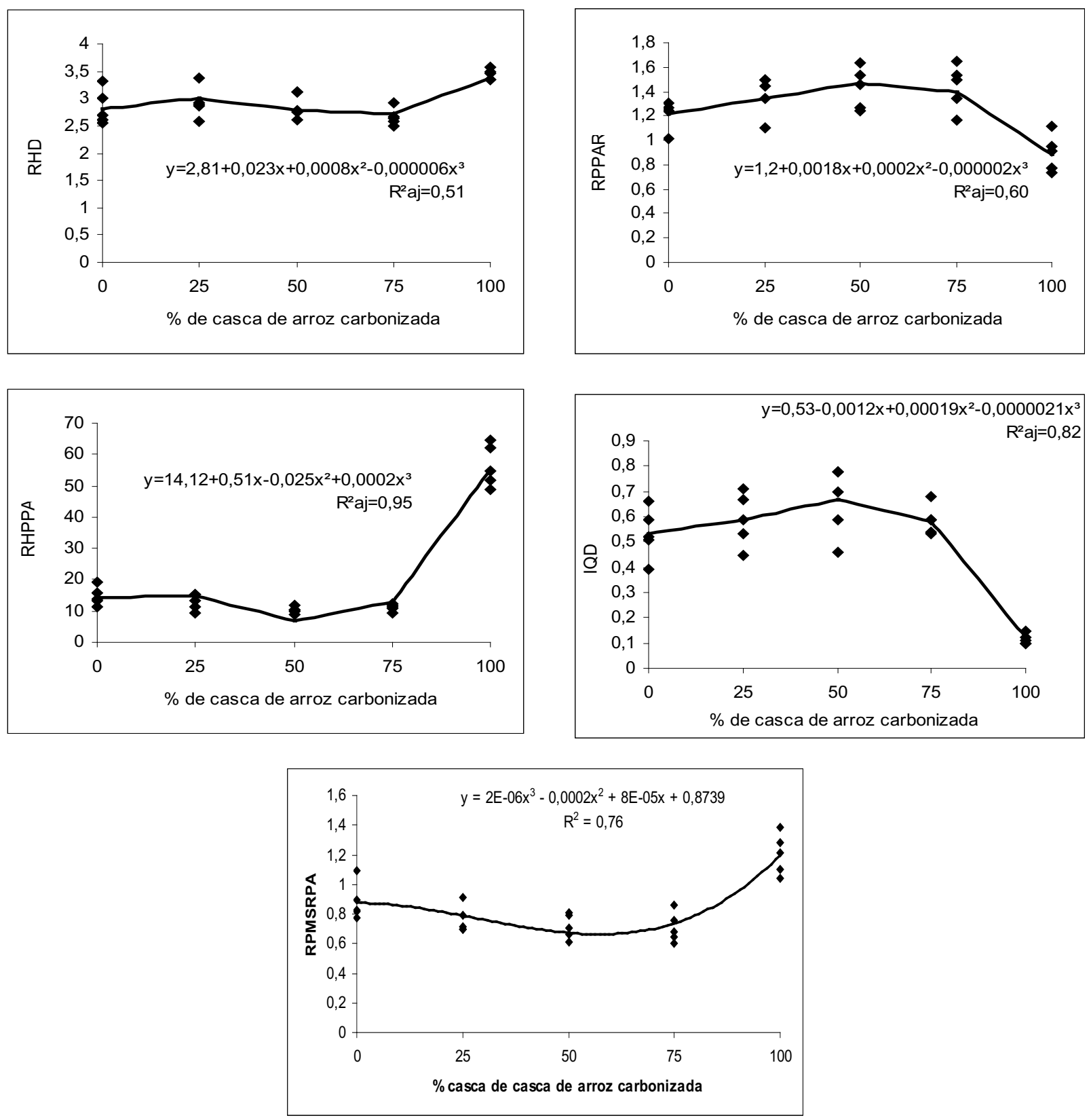

Figura 3. Regressões dos índices de qualidade para produção de mudas de Enterolobium contortisiliquum, em função da percentagem de casca de arroz carbonizada adicionada ao solo (RHD: relação entre a altura da parte aérea e o diâmetro do coleto; RPPAR: peso da massa seca do sistema radicular; RHPPA: relação entre a altura e o peso da massa seca da parte aérea ; IQD: índice de qualidade de Dickson; RPMSRPA: relação entre peso de matéria seca do sistema radicular e o peso de matéria seca da parte aérea).

Para mudas de Apuleia leiocarpa, observa-se uma diminuição nos índices IQD e RPPAR com adição de mais de $50 \%$ de CAC no substrato. No entanto, a relação RHPA aumenta com adição de CAC no substrato (Figura 4). 

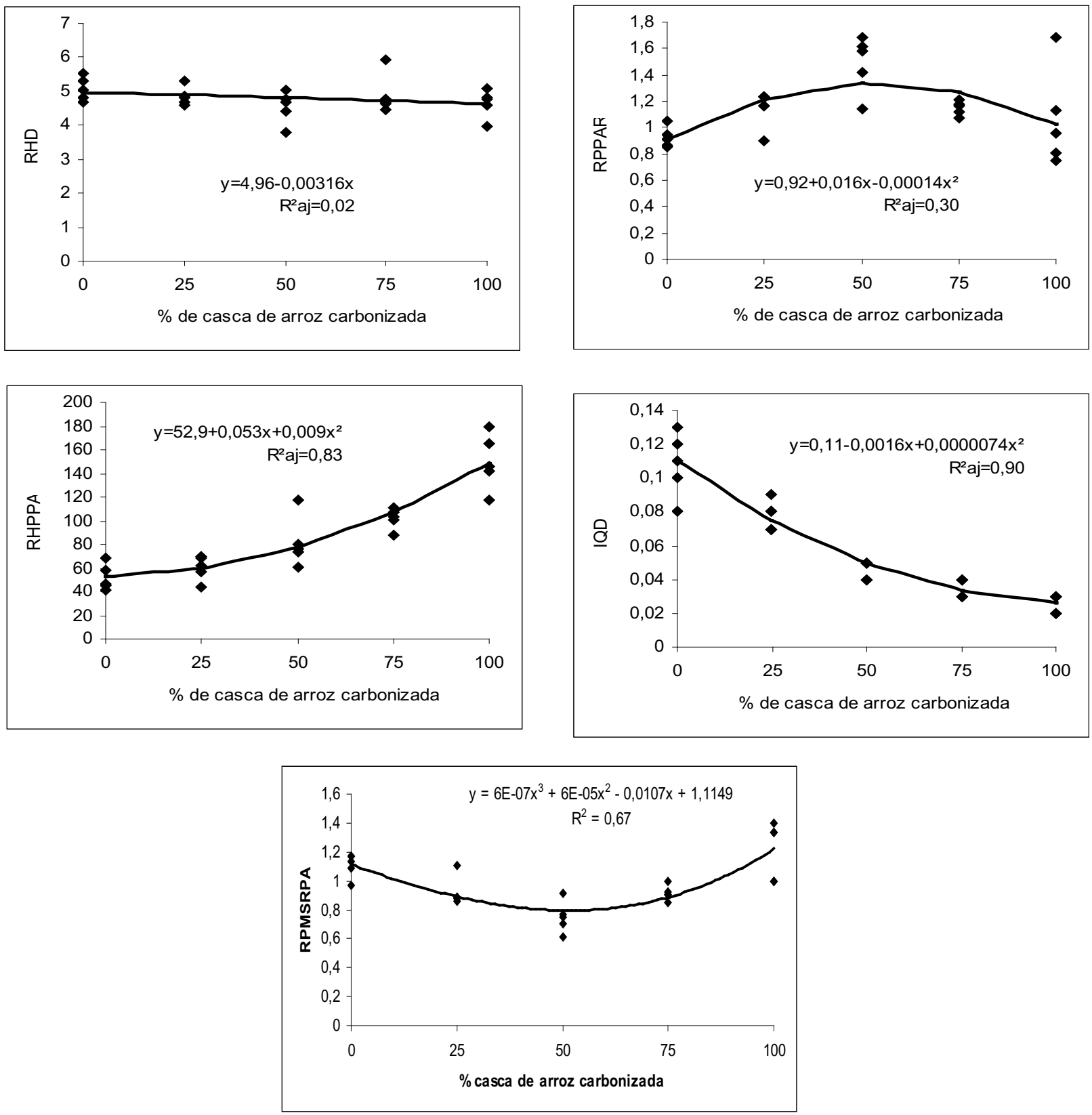

Figura 4. Regressões dos índices de qualidade para produção de mudas de Apuleia leiocarpa, em função da percentagem de casca de arroz carbonizada adicionada ao solo (RHD: relação entre a altura da parte aérea e o diâmetro do coleto; RPPAR: peso da massa seca do sistema radicular; RHPPA: relação entre a altura e o peso da massa seca da parte aérea ; IQD: índice de qualidade de Dickson; RPMSRPA: relação entre peso de matéria seca do sistema radicular e o peso de matéria seca da parte aérea).

Nota-se que para ambas as espécies estudadas o índice de qualidade RHD foi menor que 10, padrão recomendado por Birchler et al. (1998). Esta constatação também foi verificada no estudo de JOSÉ et al. (2005) com Schinus terebinthifolius. É evidente que quanto menor for à média dos diâmetros de colo, maior é o resultado do índice de qualidade RHD. Carneiro (1995) comenta quando o índice de qualidade RHD for igual a 10 indica má qualidade das mudas pelo desequilíbrio entre a média de altura da parte aérea e a do seu diâmetro do colo. 
Estudo realizado por Fonseca et al. (2002), teve como objetivo verificar a influência do período de permanência das mudas sob sombreamento nos parâmetros empregados na avaliação da qualidade das mudas de Trema micrantha. Os autores observaram que ocorreu comportamento linear decrescente do Índice de Qualidade de Dickson em função do aumento do período sob sombreamento, para avaliações aos 90 e 120 dias, e quadrático (ponto mínimo aos 138 dias), para avaliação aos 150 dias após a emergência. As mudas com maiores Índices de Qualidade de Dickson apresentaram maiores valores de diâmetro do coleto, massa seca da parte aérea, do sistema radicular e total, e menores valores da relação parte aérea/sistema radicular e da relação altura da parte aérea/diâmetro do coleto.

Estabelecendo como padrão o valor mínimo do Índice de Qualidade de Dickson em 0,20 para as mudas produzidas em recipientes de 50 ou $60 \mathrm{ml}$, como recomendado por Hunt (1990), observa-se que as mudas de Trema micrantha de acordo com Fonseca et al. (2002), somente atingiram esse valor a partir dos 120 dias após a emergência, com 45 e 60 dias sob sombreamento, indicando que apresentam qualidade para serem plantadas no campo.

O Índice de Qualidade de Dickson, segundo Fonseca et al. (2002) é um bom indicador da qualidade das mudas, pois no seu cálculo são consideradas as robustezes e o equilíbrio da distribuição da biomassa na muda, ponderando os resultados de vários parâmetros importantes empregados para avaliação da qualidade.

O peso de matéria seca das raízes tem sido reconhecido por diferentes autores como um dos mais importantes e melhores parâmetros para se estimar a sobrevivência e o crescimento inicial das mudas no campo (GOMES, 2001). Caldeira et al. (2008), observaram que mudas de Schinus terebinthifolius produzidas com $40 \%$ do composto orgânico $+60 \%$ de terra de subsolo foram superiores estatisticamente aos demais tratamentos no que se refere ao índice de qualidade MSA/MSR (massa seca área/massa de raiz). Nesse sentido, segundo Caldeira et al. (2008), deve-se dizer que a relação parte área e raiz nas mudas deve ser de 2:1 e a relação raiz e parte aérea 1:2. É importante analisar essa relação quando as mudas vão para o campo, pois a parte aérea das mudas não dever ser muito superior que a da raiz em função dos possíveis problemas no que se refere à absorção de água para a parte aérea.

Considerando que a relação peso de matéria seca da parte aérea/peso de matéria seca das raízes depende de dois parâmetros destrutivos para sua determinação, que os dados não permitem maiores conclusões e que é uma relação contraditória para o crescimento de mudas no campo (BURNETT, 1979), não deverá ser indicada como índice para determinação do padrão de qualidade de mudas de Eucalyptus grandis (GOMES et al., 2002), e provavelmente para outras espécies também.

Segundo Gomes et al. (2002) observaram que a relação altura da parte aérea/peso de matéria seca da parte aérea de mudas de Eucalyptus gradis apresentou a maior contribuição relativa, mostrando a sua importância, apesar de na sua determinação ser preciso levar em consideração um parâmetro destrutivo, que é o peso de matéria seca.

A altura é considerada como um dos parâmetros mais antigos na classificação e seleção de mudas (PARVIAINEN, 1981), e ainda continua apresentando uma contribuição importante, podendo assim ser indicada como um parâmetro para essa avaliação. Nesse sentido, as maiores alturas corresponderam, no campo, à maior taxa de sobrevivência e ao maior crescimento inicial para Pinus radiata (PAWSEY, 1972).

$\mathrm{O}$ quociente obtido por esses dois fatores, ou seja, MSA/MSR e H/MSA (altura/massa seca aérea) não é comumente usado como um índice para avaliar o padrão de qualidade de mudas, mas pode ser de grande valia se utilizado, principalmente para predizer o potencial de sobrevivência da muda no campo (GOMES, 2001). 
Gomes et al. (2002), comentam que adoção da altura e da relação altura/peso de matéria seca da parte aérea deve ser considerada, pelo fato de terem sido parâmetros que apresentaram boa contribuição relativa ao padrão de qualidade das mudas. No entanto, a adoção somente da altura para estimar a qualidade de mudas de Eucalyptus grandis poderá ser utilizada, uma vez que ela foi um dos parâmetros que apresentou boa contribuição relativa, além de sua medição ser muito fácil e não ser um método destrutivo.

Para avaliar a qualidade de mudas de Eucalyptus grandis com a idade de 60 dias, Gomes et al. (2002), analisaram que a altura e o diâmetro do coleto seriam os parâmetros a ser medido, uma vez que o primeiro e a relação dos dois representam juntos mais de $80 \%$ da contribuição relativa.

É sabido que a altura da parte aérea é de fácil medição e, portanto, sempre foi utilizada com eficiência para estimar o padrão de qualidade de mudas nos viveiros (CARNEIRO, 1995; GOMES, 2001; CALDEIRA et al., 2000a; 2000b; CALDEIRA et al., 2008), sendo considerada também como um dos mais importantes parâmetros para estimar o crescimento no campo (MEXAL; LANDS, 1990; REIS et al., 1991), além do que sua medição não acarreta a destruição das mudas, sendo tecnicamente aceita como uma boa medida do potencial de desempenho das mudas (MEXAL; LANDS, 1990).

A altura da parte aérea combinada com o diâmetro do coleto constitui um dos mais importantes parâmetros morfológicos para estimar o crescimento das mudas após o plantio definitivo no campo (CARNEIRO, 1995).

O valor resultante da divisão da altura da parte aérea pelo diâmetro do coleto exprime um equilíbrio de crescimento, relacionando esses dois importantes parâmetros morfológicos em apenas um índice (CARNEIRO, 1995), também denominado de quociente de robustez, sendo considerado um dos mais precisos, pois fornece informações de quanto delgada está a muda (JOHNSON; CLINE, 1991).

Segundo Caldeira et al. (2008), os resultados do índice H/D (altura/diâmetro) mostraram equilíbrio superior de crescimento em mudas de Schinus terebinthifolius no tratamento com 100\% do substrato do viveiro $(50 \%$ de terra de subsolo $+30 \%$ de esterco bovino $+20 \%$ de casca de arroz carbonizada) e um equilíbrio inferior no tratamento com $100 \%$ de composto orgânico e $40 \%$ do composto orgânico $+60 \%$ de terra de subsolo.

Para ambas as espécies estudadas, no geral, apresentam comportamento diferente quanto aos índices de qualidade. Importante observação a ser feita, segundo Carneiro (1995) é que qualquer índice sugerido leva em consideração dois fatores: a espécie e o sítio. Deve-se ressaltar que densidade de mudas e fertilidade do substrato exerce influência nos valores que determinam os índices de qualidade das mudas.

Analisando as médias da Razão entre massa seca radicial/massa seca da parte aérea observa-se que para ambas as espécies o tratamento 5 apresenta os maiores valores (1,21 para Garapeira e 1,20 para Tamboril-da-mata), e o menor índice, também para ambas, no tratamento 3 (0,75 para Garapeira e 0,72 para Tamboril-da-mata), indicando uma semelhança no desenvolvimento vegetativo das espécies em ambientes similares.

De acordo com Clarkson (1985) a Razão é comumente maior em ambiente de baixa fertilidade, podendo ser considerada uma estratégia da planta para retirar o máximo de nutrientes naquela condição. Conforme Daniel et al. (1997), essa Razão aumenta à medida que diminui o suprimento de nutrientes, característica observada no tratamento T5 (100\% de $\mathrm{CAC}+0 \%$ de Solo) para ambas as espécies. Caldeira et al. (2000a; 2000b), cometam que a Razão é em função da espécie, do tipo de substrato a ser utilizado na produção de mudas, bem como da fertilidade do mesmo.

\section{Conclusões}

A utilização de diferentes proporções de casca de arroz carbonizada no solo influenciou 
significativamente nos parâmetros biométricos e índices de qualidade das mudas de Enterolobium contortisiliquum e Apuleia leiocarpa.

As espécies estudadas apresentaram comportamento diferente em relação à proporção de casca de arroz carbonizada e solo, na constituição do substrato.

Proporção crescente de casca de arrozcarbonizada na constituição do solo diminui o desenvolvimento de mudas de Apuleia leiocarpa.

Para a produção de mudas de Enterolobium contortisiliquum com um adequado padrão de qualidade recomenda-se utilizar $50 \%$ de CAC + $50 \%$ de solo.

\section{Referências}

AGUIAR, I. B.; ISMAEL, J. J.; BANZATTO, D. A.; VALERI, S. V.; ALVARENGA, S. F.; CORRADINE, L. Efeitos da composição do substrato para tubetes no comportamento de Eucalyptus grandis hill ex maiden no viveiro e no campo. Circular Técnica, Piracicaba: IPEF, n.180, p. 1-10, 1992.

BIRCHLER, T.; ROSE, R. W.; ROYO, A.; PARDOS, M. La planta ideal: revision del concepto, parametros definitorios e implementaction practica. Investigacion Agraria, Sistemas y Recursos Forestales, Madrid, v. 7, n. 1/2, p. 109-121, 1998.

BURNETT, A. N. New methods for measuring root growth capacity: their value in assessing lodgepole pine stock quality. Canadian Journal of Forest Research, Ottawa, v. 9, p. 63-67, 1979.

CALDEIRA, M. V. W.; ROSA, G. N.; FENILLI, T. A. B.; HARBS, R. M. P. Composto orgânico na produção de mudas de aroeira-vermelha. Scientia Agraria, Curitiba, v. 9, n. 1, p. 27-33, 2008.

CALDEIRA, M. V. W.; SCHUMACHER, M. V.; BARICHELLO, L. R.; VOGET, H. L. M. ; OLIVEIRA, L. S. Crescimento de mudas de Eucalyptus saligna Smith em função de diferentes doses de vermicomposto. Revista Floresta, Curitiba, v. 28, n. 1/2, p. 19-30, 2000a.

CALDEIRA, M. V. W.; SCHUMACHER, M. V.; TEDESCO. N. Crescimento de mudas de Acacia mearnsii em função de diferentes doses de vermicomposto. Scientia Forestalis, Piracicaba, n. 57, p. 161-170, jun. 2000b.

CARNEIRO, J. G. A. Produção e controle de qualidade de mudas florestais. Curitiba: UFPR/FUPEF/ UENF, 1995. 451p.
CLARKSON, D. T. Adaptações morfológicas e fisiológicas das plantas a ambientes de baixa fertilidade. In: SIMPÓSIO SOBRE RECICLAGEM DE NUTRIENTES E AGRICULTURA DE BAIXOS INSUMOS NOS TRÓPICOS, 1985, Ilhéus. Anais... Ilhéus: CEPLAC/ SBSC, 1985. p. 45-75.

DANIEL, O.; VITORINO, A. C. T.; ALOISI, A. A.; MAZZOCHIN, L. TOKURA, A. M.; PINHEIRO, E. R.; SOUZA, E. F. Aplicação de fósforo em mudas de Acacia mangium. Revista Árvore, Viçosa, v. 21, n. 2, p. 163-168, 1997.

DELLA, V. P.; HÜHN, I.; HOTZA, D. Caracterização de cinza de casca de arroz para uso como matéria-prima na fabricação de refratários de sílica. Química Nova, São Paulo, v. 24, n. 6, p. 778-782, 2001.

DICKSON, A.; LEAF, A. L.; HOSNER, J. F. Quality appraisal of while spruce and white pine seedling stock in nurseries. Forestry Chronicle, Canada, v. 36, n. 1, p. 11-13, 1960.

DURYEA, M. L. Evaluating seedling quality importance to reforestation. In: . Evaluating seedling quality principles, procedures, and predictive abilities of major tests. Corvallis: Forest Research Laboratory Oregon State University, 1985. p. 1-6.

EMPRESA BRASILEIRA DE PESQUISA AGROPECUÁRIA - EMBRAPA. Sistema brasileiro de classificação de solos. 2. ed. Rio de Janeiro: Embrapa Solos, 2006. 306p.

FERNANDES, P. S.; FERREIRA, M. C.; STAPE, J. L. Sistemas alternativos de produção demudas de Eucalyptus. In: CONGRESSO FLORESTAL BRASILEIRO, 5., 1986, Olinda. Anais... São Paulo: Sociedade Brasileira de Silvicultura, 1986. p. 73.

FONSECA, É. P.; VALÉRI, S. V.; MIGLIORANZA, É.; FONSECA, N. A. N.; COUTO, L. Padrão de qualidade de mudas de Trema micrantha (L.) Blume, produzidas sob diferentes períodos de sombreamento. Revista Árvore, Viçosa, v. 26, n. 4, p. 515-523, 2002.

GOMES, J. M.; COUTO, L.; LEITE, H. G.; XAVIER, A.; GARCIA, S. L. R. Parâmetros morfológicos na avaliação da qualidade de mudas de Eucalyptus grandis. Revista Árvore, Viçosa, v. 26, n. 6, p. 655-664, 2002.

GOMES; J. M. Parâmetros morfológicos na avaliação da qualidade de mudas de Eucalyptus grandis, produzidas em diferentes tamanhos de tubetes e de dosagens de N-P-K. 2001. Tese (Doutorado em Ciências Florestais) Universidade Federal de Viçosa, Viçosa.

GONÇALVES; J. L. M., POGGIANI; F. Substrato para produção de mudas florestais. In: CONGRESSO LATINO AMERICANO DE CIÊNCIA DO SOLO. Águas de 
Lindóia, 1996. Resumos... Piracicaba. Sociedade Latino Americano de Ciência do Solo, 1996. 1 CD-ROM.

GUERRINI, I. A.; TRIGUEIRO, R. M. Atributos físicos e químicos de substratos compostos por biossólidos e casca de arroz carbonizada. Revista Brasileira de Ciências do Solo, Campinas, v. 28, n. 6, p. 1069-1076, 2004.

HUNT, G. A. Effect of styroblock design and Cooper treatment on morphology of conifer seedlings. In: TARGET SEEDLING SYMPOSIUM, MEETING OF THE WESTERNFORESTNURSERYASSOCIATIONS, GENERAL TECHNICAL REPORT RM-200, 1990, Roseburg. Proceedings... Fort Collins: United States Departament of Agriculture, Forest Service, 1990. p. 218-222.

JOHNSON, J. D.; CLINE, P. M. Seedling quality of southern pines. In: DUREYA, M. L.; DOUGHERTY, P. M. (Ed.). Forest regeneration manual. Dordrecht: Kluwer Academic Publishers, 1991. p. 143-16.

KLEIN, V. A.; CAMARA, R. K.; SIMON, M. A.; DIAS, S. T. Casca de arroz carbonizada como condicionador de substrato. In: FURLANI, A. M. C. Caracterização, manejo e qualidade de substrato para produção de plantas. Campinas: Instituto Agronômico, 2002. 95p. (Documentos IAC, n. 70).

MEXAL, J. L.; LANDS, T. D. Target seedling concepts: height and diameter. In: TARGET SEEDLING SYMPOSIUM, MEETING OF THE WESTERN FOREST NURSERY ASSOCIATIONS, GENERAL TECHNICAL REPORT RM-200, 1990, Roseburg. Proceedings... Fort. Collins: United States Departament of Agriculture, Forest Service, 1990. p. 17-35.

MINAMI, K. Produção de mudas de alta qualidade em horticultura. São Paulo: Fundação Salim Farah Maluf, 1995. 128p.

OLIVEIRA, R. B.; LIMA, J. S. S.; SOUZA, C. A. M.; SILVA, S. A.; MARTINS FILHO, S. Produção de mudas de essências florestais em diferentes substratos e acompanhamento do desenvolvimento em campo. Ciência e Agrotecnologia, Lavras, v. 32, n. 1, p. 122-128, 2008.

PARVIAINEN, J. V. Qualidade e avaliação de qualidade de mudas florestais. In: SEMINÁRIO DE SEMENTES E VIVEIROS FLORESTAIS, 1., 1981, Curitiba. Anais... Curitiba: FUPEF, 1981. p. 59-90.

PAWSEY, C. K. Survival and early developmment of Pinus radiata as influencied by size of planting stock. Australian Forest Research, Canberra, v. 5, n. 4, p. 1329, 1972.
REIS, M. G. F.; REIS, G. G.; REGAZZI, A. J.; LELES, P. S. S. Crescimento e forma de fuste de mudas de jacarandá-da-bahia (Dalbergia nigra Fr. Allem.) sob diferentes níveis de sombreamento e tempo de cobertura. Revista Árvore, Viçosa, v. 15, n. 1, p. 23-34, 1991.

SAIDELLES, F. L. F.; WIELEWICKI, A. P., SCCOTI, M. S. V.; SALLES, A. M.; ZINI, R. O. Utilização de resíduo agroindustrial para produção de mudas de Pinus elliotti. In: SIMPÓSIO DE ENSINO, PESQUISA E EXTENSÃO, 9., 2006, Santa Maria. Anais... Santa Maria: UNIFRA, 2006a. p. 746. CD-ROM.

SAIDELLES, F. L. F.; WIELEWICKI, A. P., SCCOTI, M. S. V.; MICHELOTTI, D.; MARQUESAN, F. S. L. Influência do uso da casca de arroz carbonizada na qualidade de mudas de cipreste Cupressus lusitanico Mill. In: SIMPÓSIO DE ENSINO, PESQUISA E EXTENSÃO, 9., 2006, Santa Maria. Anais... Santa Maria: UNIFRA, 2006b. p. 743. CD-ROM.

SAIDELLES, F. L. F.; WIELEWICKI, A. P.; FLORES, A. V.; CUNHA, A. C. M.; SILVA, A. S. Efeito do substrato na qualidade de mudas de Eucalyptus saligna no viveiro e no campo. In: CONGRESSO BRASILEIRO DE CIENCIA DO SOLO, 2006, Passa Fundo. Anais... Passo Fundo: CBSC, 2006c. CD-ROM.

SALlES, A. S.; SILVA, R. F.; MÜHLEN, F. G. V.; SAIDELLES, F. L. F. Uso da casca de arroz carbonizada na composição do substrato para produção de mudas de Acacia mearnsii de willd. In: SIMPÓSIO DE ENSINO, PESQUISA E EXTENSÃO, 9., 2006, Santa Maria. Anais... Santa Maria: UNIFRA, 2006. p. 293. CD-ROM.

SARTORI, M. G. B. O clima de Santa Maria, RS: do regional ao urbano. 1979. 167p. Dissertação (Mestrado em Geografia) - Universidade de São Paulo, São Paulo.

TABAJARA, S. M.; COLÔNIA, E. J. Casca de arroz e meio ambiente. Revista Lavoura Arrozeira, Porto Alegre, v. 39, n. 369, p. 10-12, 1986.

TEDESCO, M. J.; GIANELlO, C.; BISSANI, C. A.; BOHNEN, H.; VOLKWEISS, S .J. Análises de solos, plantas e outros materiais. 2. ed. Porto Alegre: UFRGS, 1995. (Boletim Técnico, n. 5).

VALlONE, H. S.; GUIMARÃES, R. J.; SOUZA, C. A. S.; CARVALHO, J. A.; FERREIRA, R. S.; OLIVEIRA, S. Substituição do substrato comercial por casca de arroz carbonizada para a produção de mudas de cafeeiro em tubetes na presença de polímero hidrorretentor. Ciência Agrotécnica, Lavras, v. 28, n. 3, p. 598-604, 2004.

WENDLING, I.; GATTO, A. Substratos, adubação e irrigação na produção de mudas. Viçosa: Aprenda Fácil, 2002. 166p. 